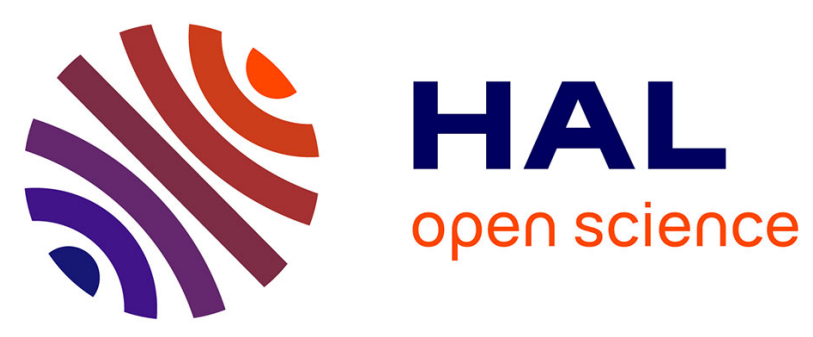

\title{
Electrochemical Harvesting of Photosynthetic Electrons from Unicellular Algae Population at the Preparative Scale by Using 2,6-dichlorobenzoquinone
}

Guillaume Longatte, Fabrice Rappaport, Francis-André Wollman, Manon Guille-Collignon, Frédéric Lemaître

\section{To cite this version:}

Guillaume Longatte, Fabrice Rappaport, Francis-André Wollman, Manon Guille-Collignon, Frédéric Lemaître. Electrochemical Harvesting of Photosynthetic Electrons from Unicellular Algae Population at the Preparative Scale by Using 2,6-dichlorobenzoquinone. Electrochimica Acta, 2017, 10.1016/j.electacta.2017.03.124 . hal-01494463

\section{HAL Id: hal-01494463 \\ https://hal.sorbonne-universite.fr/hal-01494463}

Submitted on 23 Mar 2017

HAL is a multi-disciplinary open access archive for the deposit and dissemination of scientific research documents, whether they are published or not. The documents may come from teaching and research institutions in France or abroad, or from public or private research centers.
L'archive ouverte pluridisciplinaire HAL, est destinée au dépôt et à la diffusion de documents scientifiques de niveau recherche, publiés ou non, émanant des établissements d'enseignement et de recherche français ou étrangers, des laboratoires publics ou privés. 


\title{
Electrochemical Harvesting of Photosynthetic Electrons from Unicellular Algae Population at the Preparative Scale by Using 2,6-dichlorobenzoquinone
}

Guillaume Longatte, ${ }^{\mathrm{a}}$ Fabrice Rappaport, ${ }^{\mathrm{b}}$ Francis-André Wollman, ${ }^{\mathrm{b}}$

Manon Guille-Collignon, ${ }^{\mathrm{a}}$ Frédéric Lemaître ${ }^{\mathrm{a} *}$

a) Ecole Normale Supérieure-PSL Research University, Département de Chimie, Sorbonne Universités - UPMC Univ Paris 06, CNRS UMR 8640 PASTEUR, 24, rue Lhomond, 75005 Paris, France.

b) Laboratoire de physiologie membranaire et moléculaire du chloroplaste, CNRS, UPMC UMR 7141, I.B.PC., 13 rue Pierre et Marie Curie, 75005 Paris, France

Number of tables: 1

Number of figures: 4

\begin{abstract}
Oxygenic photosynthesis is the process used by plants, cyanobacteria or algae to convert the solar energy into a chemical one from the carbon dioxide reduction and water oxidation. In the past years, many strategies were implemented to take benefits from the overall low yield of this process to extract photosynthetic electrons and thus produce a sustainable photocurrent. In practice, electrochemical tools were involved and the principle of electrons harvestings was related to the step of electron transfer between the photosynthetic organism and a collecting electrode. In this context, works involving an algae population in suspension were rather scarce and rather focus on the grafting of the photosynthetic machinery at the electrode surface. Based on our previous works, we report here the implementation of an electrochemical set-up at the preparative scale to produce photocurrents. An algae suspension, i.e. an intact biological system to ensure culture and growth, was involved in presence of a centimeter-sized carbon gauze as the collecting electrode. The spectroelectrochemical cell contains $16 \mathrm{~mL}$ of suspension of a Chlamydomonas reinhardtii mutant with an appropriate mediator (2,6-DCBQ). Under these conditions, stable photocurrents were recorded over $1 \mathrm{~h}$ whose magnitude depends on the quinone concentration and the light illumination.
\end{abstract}

Keywords: photosynthesis; ; ; ; ; , quinones, electrochemistry, Chlamydomonas reinhardtii algae, photosystem II, photocurrent 


\section{Introduction}

In the current context of renewable energies, sunlight is the most abundant and sustainable source of energy available on Earth.[1-3] In this context, photosynthesis is now considered as one of the strategies to take benefits from the solar energy. Indeed, photosynthesis is the biological process involved by Nature to feed the biosphere with reduced carbon. However, it only uses a very small fraction from the sunlight energy (the overall yield is few $\%$ of the total energy available from sunlight being converted into chemical energy),[4] while the photochemical converters (Photosystems I and II) remain very efficient.[5] Among several limitations which lower this yield, a prominent saturation of the photochemical conversion comes from the kinetic limiting transfer step located downstream of Photosystem II (see Figure 1). Therefore, under high-light conditions, Photosystem II cannot fully release its charge. As a consequence, the overall yield is intrinsically decreased because PSII does not reach its maximal turnover rate. Furthermore, the PSII primary electron acceptors accumulation in their reduced state will lead to photoinhibition, that is the formation of reactive species which can damage the photosynthetic chain.[6] The cost associated with the sustained maintenance of the photosynthetic machinery (damage/repair cycles) also contribute to diminish the global yield. Paradoxically, the apparently disappointing performance of photosynthesis makes it a promising fuel-producing factory because this saturation of the photochemical conversion while quantum efficiencies of photosystems remain excellent would suggest that photosynthesis is an unexploited reservoir to produce electricity by harvesting electrons among the photosynthetic chain under high-light conditions.

In that way, recent strategies mainly involved a collecting electrode for harvesting the electrons from the photosynthetic organism though with different biological targets or electrochemical set-ups. For instance, benefits could be taken from the good efficiencies of photosystems by grafting isolated PSII or PSI on the electrode surface.[7-11] Using native photosynthetic membranes immobilized on the working electrode[12, 13] also helps to avoid the step of biochemical purification of photosystems.[14-18] Moreover the electrical connectivity between the electrode and the photosynthetic unit can be enhanced by using redox polymers, nanotubes, nanoparticles or exogenous mediators. Finally, intact biological systems like cyanobacteria[19-23] or algae[24, 25] can be considered. This is a more long lasting approach because it potentially ensures the culture and proliferation of the photosynthetic organisms during the electrons extraction. However, the electron harvesting is made more difficult because of a restricted access to the photosynthetic chain due to extra and 
intracellular membranes or other aqueous compartments to cross. This is probably why works involving cell suspensions are often limited to the analytical level.[26-28]

In that purpose, we demonstrated in the past the ability of several exogenous quinones (chloro, methyl and phenyl derivatives) to extract photosynthetic electrons from the green unicellular algae Chlamydomonas reinhardtii.[29, 30] In the present work, we report the implementation of an electrochemical set-up aimed to use a suspension of a Chlamydomonas reinhardtii mutant at the preparative scale. An appropriate exogenous quinone will act as an electron carrier from the electrons harvesting to its re-oxidation at the collecting electrode surface. Photocurrents from 10 to $60 \mu \mathrm{A} . \mathrm{cm}^{-2}$ were effectively recorded, depending on the quinone concentration as well as the light illumination.

\section{Experimental}

\subsection{Cell culture and preparation}

Chlamydomonas reinhardtii $\Delta$ petA mutant was grown in Tris Acetate Phosphate medium (TAP) containing Tris base $\left(20 \mathrm{mmol} . \mathrm{L}^{-1}\right), \mathrm{NH}_{4} \mathrm{Cl}\left(7 \mathrm{mmol} . \mathrm{L}^{-1}\right), \mathrm{MgSO}_{4}\left(0.83 \mathrm{mmol} . \mathrm{L}^{-1}\right), \mathrm{CaCl}_{2}(0.45$ mmol.L $\left.{ }^{-1}\right), \mathrm{K}_{2} \mathrm{HPO}_{4}\left(1.65 \mathrm{mmol} . \mathrm{L}^{-1}\right), \mathrm{KH}_{2} \mathrm{PO}_{4}\left(1.05 \mathrm{mmol} . \mathrm{L}^{-1}\right)$ at $25^{\circ} \mathrm{C}$ under rather dim light conditions $\left(50 \mu \mathrm{E} \cdot \mathrm{m}^{-2} \cdot \mathrm{s}^{-1}\right)$ to a cell suspension at a concentration of $10^{7}$ cells.mL $\mathrm{L}^{-1}$, then centrifugated at 4000 tour. $\mathrm{min}^{-1}$ and then re-suspended into PBS medium for electrochemical experiments (see below) to reach a final steady concentration of $10^{7}$ cells. $\mathrm{mL}^{-1}$ that corresponds to stable conditions for algae.

\subsection{Chemical materials and solutions preparation}

All chemicals have been purchased from sigma Aldrich and have been used without any further purification. Quinones were dissolved in absolute ethanol in order to make mother concentrated solutions. Appropriate small volumes of such quinone solutions were thus directly added to the algae suspension for subsequent electrochemical experiments (see below).

\subsection{Electrochemical experiments}

\subsubsection{Photocurrent recording}

A home-made spectroelectrochemical cell was used (see Figure 2). Experiments were achieved in TAP supplemented with PBS to reach an adapted ionic strength $\left(\sim 150 \mathrm{mmol}^{\left.-\mathrm{L}^{-1}\right)}\right.$ to electrochemical measurements. In practice, $7.4 \%$ of a concentrated PBS (6.66 times more concentrated than the one used for cyclic voltammetry) is added to the TAP medium described above. A carbon gauze (geometric area $=1 \mathrm{~cm}^{2}$, Mersen, Courbevoie, France) was used as the working electrode, a platinum plate as the counter electrode, and an $\mathrm{Ag} / \mathrm{AgCl} 1 \mathrm{~mm}$ diameter wire as the reference electrode. In order to perform chronoamperometric measurements at constant potential, the set-up corresponds to an adapted three-compartment cell by separating the counter electrode from the electrolysis medium with a fritted glass of medium porosity. All the measurements were carried out at $25{ }^{\circ} \mathrm{C}$. The control of the applied potential value and the acquisition of the current-time curves were achieved by the mean of a QuadStat potentiostat supplemented with an e-corder data recorder (eDAQ).

Illumination was achieved by the mean of a JTS spectrophotometer (Biologic). The actinic (excitation) light was provided by a red LED $(640 \mathrm{~nm})$ at two incident lights $\left(135\right.$ or $\left.340 \mu \mathrm{E} \cdot \mathrm{m}^{-2} \cdot \mathrm{s}^{-1}\right)$. 
Practically, after growth and centrifugation, the Chlamydomonas reinhardtii cells are re-suspended in PBS-TAP medium and $16 \mathrm{~mL}$ of solution (with a cell concentration of $10^{7}$ cells. $\mathrm{mL}^{-1}$ ) are transferred in the spectroelectrochemical cell. In order to avoid sedimentation of the algae, the solution was stirred with an overhead stirrer (Ref: VOS 14, VWR international) at 100 r.p.m. The biased potential was set in darkness at $0.65 \mathrm{~V}$ vs. $\mathrm{Ag} / \mathrm{AgCl}$ in absence of 2,6-DCBQ. The current was then recorded every $2 \mathrm{~s}$. After stabilization of the baseline (needed to remove the high capacitive current resulting from the high electrode surface area), 2,6-DCBQ (previously dissolved in ethanol) is added to reach the given concentration $\left(40 ; 75\right.$ or $100 \mu$ mol. $\left.\mathrm{L}^{-1}\right)$. A current increase $(\sim 10 \mu \mathrm{A})$ thus appeared, probably due to the interaction between the quinones and the respiratory chain.[29] After a new stabilization of the baseline, illumination is performed during half an hour. The end of the recording only occurs when the current returned to the baseline. The variations of light-dependent current are obtained by fitting the baseline and substracting it from the row data.

\section{Results and discussion}

\subsection{Implementation of the experimental set-up}

Among various substituted quinones, 2,6-dichlorobenzoquinone (2,6-DCBQ) was previously demonstrated to be one of the best one to extract photosynthetic electrons from PSII.[29, 30] Assuming this harvesting leads to the hydroquinone form, electrochemistry is an appropriate tool to restore the active quinone form. As a consequence, using an efficient collecting electrode is needed for chronoamperometry experiments. It can be achieved if considering a high surface area electrode within the cell suspension solution. We thus considered a home-made spectroelectrochemical cell (see Figure 2) with a centimeter sized (geometric size) carbon gauze as a working electrode. Its potential is poised at $+650 \mathrm{mV} v \mathrm{Ag} / \mathrm{AgCl}$ in the experiments for ensuring the oxidation of the hydroquinone form (see Supporting Information). As a proof of concept, the algae considered in this work (as well as the light incident flows; see below) will be those already investigated in previous fluorescence measurements in order to establish consistent results with the intrinsic PSII acceptor ability of 2,6DCBQ determined elsewhere.[29] This is why a mutant of Chlamydomonas reinhardtii, DpetA was involved (see Figure 1).[31] In this mutant, no significant light induced electron transfer can occur unless when added quinones provide a way to specifically allow the electron harvesting (and thus the produced photocurrent from chronoamperometry experiments) directly from PSII.

\subsection{Photocurrent recordings}

Two representative experiments of photocurrent production are displayed in Figure 3. The algae suspension is illuminated in presence of 2,6-DCBQ when a potential value of $+650 \mathrm{mV}$ vs $\mathrm{Ag} / \mathrm{AgCl}$ is applied at the carbon gauze collecting electrode. After switching on the light $\left(\mathrm{I}^{\circ}=340 \mu \mathrm{E} \cdot \mathrm{m}^{-2} \cdot \mathrm{s}^{-1}\right)$, a current slowly increases as a function of the time until reaching a stationary value. The lightdependence of this current is evidenced by switching off the light. The corresponding decrease and return to the baseline demonstrates that the photocurrent is expectidly related to the harvesting of photosynthetic electrons by the exogenous 2,6-DCBQ and its renewal through an electrocatalytical cycle involving the collecting electrode. As evidenced in Figure 3, the steady state photocurrent magnitude depends on the quinone concentration. The same trend is observed at lower light illumination (see Figure S2 in SI). Globally, the dependences of the incident light flow and quinone concentration are summarized in Table $\mathbf{1}$ and show that the current densities recorded in this experimental configuration range from 5 to $60 \mu \mathrm{A} \cdot \mathrm{cm}^{-2}$. Such current densities are globally of the same order of magnitude as the other works aimed to harvest photosynthetic electrons while a more accurate comparison is prevented by the very different experimental conditions used in each strategy (with or without mediator, grafted photosynthetic organisms, entire photosynthetic organisms or 
subunits, illumination wavelength, light incident flow...). However, the reported photocurrents in our work correspond to a higher scale, i.e. at the preparative level. Moreover, it has to be emphasized that the photocurrents were more stable. Under illumination, the steady-state current is therefore stable over one hour and naturally returns to zero after 8 hours if illumination is constant during this period.

\subsection{Effect of the 2,6-DCBQ concentration and incident light flow}

The effects of 2,6-DCBQ concentration and light incident flow are depicted in Table 1 (and Figure S3 in SI). As an example, the steady-state photocurrent value is reduced by 4-5 when the concentration varies from 100 to $40 \mu \mathrm{mol} . \mathrm{L}^{-1}$. Such a strong decrease is consistent with the partition phenomenon previously evidenced.[29] Indeed cellular compartments (other than the thylakoid membrane where electron transfer occurs) may sequester a portion of the added quinones therefore preventing them to interfere with the thylakoid membrane. In the case of 2,6-DCBQ, the concentration of available quinones is about $20 \mu \mathrm{mol} . \mathrm{L}^{-1}$ in saturation conditions. As a consequence, the effects of a quinone concentration decrease is amplified in terms of recorded current, especially for quinone concentrations close to the value at which the sequestering compartments are saturated. Furthermore, in our conditions, the photocurrent drastically decreases when the illumination is diminished from 340 to $135 \mu \mathrm{E} \cdot \mathrm{m}^{-2} \cdot \mathrm{s}^{-1}$. This decrease ratio $(\sim 3)$ remains close to the incident light flow decrease ratio $(\sim 2,5)$. This observed dependence of the incident light flow on the photocurrent seems is agreement with an extraction phenomenon controlled by electronic harvesting efficiency rather than the reoxidation at the electrode surface since only the first step kinetically depends on the incident light flow and the quinone concentration.[30]

\subsection{Photocurrent analysis}

As evidenced above, the quinone and light dependence thus suggest a kinetic limitation by the quinone photoreduction by cells. This is confirmed by some basic calculations from the experimental currents. The area of the current-time curves $\left(\mathrm{A}_{\text {curve }}\right)$ can thus be compared to the measured steady state current ( $i_{s s}$ ). As an example, the $i_{\text {ss }}$ and $A_{\text {curve }}$ values for $I^{\circ}=340 \mu \mathrm{E} \cdot \mathrm{m}^{-2} \cdot \mathrm{s}^{-1}$ and $\mathrm{C}_{\mathrm{Q}}=100 \mu \mathrm{mol} \cdot \mathrm{L}^{-1}$ are $64 \mu \mathrm{A}$ and $133 \mathrm{mC}$ respectively (illumination time $\tau=1900 \mathrm{~s}$ ). The $\mathrm{A}_{\text {curve }} / \tau$ ratio is thus equal to 70 and close to the $i_{\mathrm{ss}}$ value. The real area during the current decrease (switching off the illumination at $\tau$ until the baseline return at $t_{f}$; see Figure 3) is measured as $A_{\text {decrease,exp }}=0.0244 \mathrm{C}$. In the case of the rate limitation by the electrochemical oxidation, the concentration of the hydroquinone form in solution should be at most equal to $100 \mu \mathrm{mol} . \mathrm{L}^{-1}$. Knowing the volume $(16 \mathrm{~mL})$ and the Faraday's law, the corresponding area during the decrease should be equal to $0.309 \mathrm{C}$, that is far from the experimental value. Such a result is confirmed by a more general trend in Figure $\mathbf{4}$ which displayed a linear relationship between $i_{\text {ss }}$ and $A_{\text {curve }} / \tau$ with a slope close to the unit $\left(\left(y=0.924 x ; R^{2}=0.9974\right)\right.$.

However, the kinetic limitation involved in the process seems more complicated to rationalize if estimating the extraction rate from the chronoamperogramms and its comparison to expected values. For instance, with $\mathrm{I}^{\circ}=340 \mu \mathrm{E} \cdot \mathrm{m}^{-2} \cdot \mathrm{s}^{-1}$ and an introduced quinone concentration of $100 \mu \mathrm{mol} . \mathrm{L}^{-1}$, $\mathrm{i}_{\mathrm{ss}}$ is about $60 \mu \mathrm{A}$, i.e. a global rate $(=\mathrm{i} / \mathrm{F})$ of about 620 pmol. $\mathrm{s}^{-1}$ of electrons. With an incident light of 340 $\mu \mathrm{E} \cdot \mathrm{m}^{-2} \cdot \mathrm{s}^{-1}$, the photochemical rate ranges from 5 to $6 \mathrm{~ms}$ per PSII center, i.e. around 200 photons. $\mathrm{s}^{-}$ ${ }^{1}$.PSII ${ }^{-1}$. Under our conditions, the PSII concentration is close to $50 \mathrm{nmol} \cdot \mathrm{L}^{-1}$ and the light beam illuminates $1 \mathrm{~mL}$ of solution. The maximum biological rate can be estimated to $10 \mathrm{nmol} . \mathrm{s}^{-1}$ of electrons. Moreover, the photosynthetic electrons extraction induced by exogenous quinone is not a quantitative process. The extraction yield $\Phi\left(\mathrm{I}^{\circ}, \mathrm{C}_{\mathrm{Q}}\right)$ is thus close to 0.55 , leading to a global rate of 5.5 nmol.s $\mathrm{s}^{-1} \cdot[29,30]$. Indeed, the expected rate should be finally equal to $5.5 \mathrm{nmol} . \mathrm{s}^{-1}$, i.e. a lower value than the expected one with a unique kinetic control by the quinone extraction step. This suggests that other competitive phenomena (being not quite fast to be neglected) can play a role on the global rate. For instance, the different membranes in algae may slow down the diffusion of reduced quinones from 
the thylakoid to the electrode surface. Furthermore, a photosynthetic chain unstability may occur due to the light (photoinhibition) or quinones itself (toxicity) at long times.

\section{Conclusion}

In this work, we took benefits from previous experiments devoted to the interaction between exogenous quinones and the photosynthetic chain of green cellular algae. An electrochemical set-up was implemented at the preparative level (centimeter size carbon gauze, volume of $16 \mathrm{~mL}$ ) to produce a photocurrent related to in the extraction of electrons from PSII. The resulting current densities validate the strategy to work with algae suspension and contribute to recent works at the preparative scale.[32, 33] Furthermore, under our experimental conditions, the process is probably controlled by the quinone extraction step while other competitive phenomena (diffusion within membranes, photoinhibition and even quinone decomposition at long times...) should be considered in future experiments for enhancing the extraction method in terms of current magnitude and stability over the illumination time.

\section{References}

[1] J. Barber, Photosynthetic energy conversion: natural and artificial, Chemical Society Reviews, 38 (2009) 185-196.

[2] M.I. Hoffert, K. Caldeira, G. Benford, D.R. Criswell, C. Green, H. Herzog, A.K. Jain, H.S. Kheshgi, K.S. Lackner, J.S. Lewis, H.D. Lightfoot, W. Manheimer, J.C. Mankins, M.E. Mauel, L.J. Perkins, M.E. Schlesinger, T. Volk, T.M.L. Wigley, Advanced technology paths to global climate stability: Energy for a greenhouse planet, Science, 298 (2002) 981-987.

[3] N.S. Lewis, D.G. Nocera, Powering the planet: Chemical challenges in solar energy utilization, Proceedings of the National Academy of Sciences of the United States of America, 103 (2006) 15729-15735.

[4] X.G. Zhu, S.P. Long, D.R. Ort, Improving Photosynthetic Efficiency for Greater Yield, in: S. Merchant, W.R. Briggs, D. Ort (Eds.) Annual Review of Plant Biology, Vol 612010, pp. 235-261.

[5] R.E. Blankenship, D.M. Tiede, J. Barber, G.W. Brudvig, G. Fleming, M. Ghirardi, M.R. Gunner, W. Junge, D.M. Kramer, A. Melis, T.A. Moore, C.C. Moser, D.G. Nocera, A.J. Nozik, D.R. Ort, W.W. Parson, R.C. Prince, R.T. Sayre, Comparing Photosynthetic and Photovoltaic Efficiencies and Recognizing the Potential for Improvement, Science, 332 (2011) 805-809. [6] T. Roach, A. Krieger-Liszkay, Regulation of Photosynthetic Electron Transport and Photoinhibition, Current Protein \& Peptide Science, 15 (2014) 351-362. 
[7] A. Badura, D. Guschin, B. Esper, T. Kothe, S. Neugebauer, W. Schuhmann, M. Roegner, Photo-induced electron transfer between photosystem 2 via cross-linked redox hydrogels, Electroanalysis, 20 (2008) 1043-1047.

[8] A. Badura, T. Kothe, W. Schuhmann, M. Roegner, Wiring photosynthetic enzymes to electrodes, Energy \& Environmental Science, 4 (2011) 3263-3274.

[9] T. Kothe, S. Poeller, F. Zhao, P. Fortgang, M. Roegner, W. Schuhmann, N. Plumere, Engineered Electron-Transfer Chain in Photosystem 1 Based Photocathodes Outperforms Electron-Transfer Rates in Natural Photosynthesis, Chemistry- A European Journal, 20 (2014) 11029-11034.

[10] R. Tel-Vered, I. Willner, Photo-bioelectrochemical Cells for Energy Conversion, Sensing, and Optoelectronic Applications, Chemelectrochem, 1 (2014) 1778-1797.

[11] F. Zhao, K. Sliozberg, M. Roegner, N. Plumere, W. Schuhmann, The Role of Hydrophobicity of Os-Complex-Modified Polymers for Photosystem 1 Based Photocathodes, Journal of the Electrochemical Society, 161 (2014) H3035-H3041.

[12] J. Lee, J. Im, S. Kim, Mediatorless solar energy conversion by covalently bonded thylakoid monolayer on the glassy carbon electrode, Bioelectrochemistry, 108 (2016) 21-27.

[13] J. Lee, S. Kim, Mediator-free solar energy conversion by the artificially installed thylakoid membrane on the functionalized electrode, Electrochemistry Communications, 49 (2014) 55-59. [14] J.O. Calkins, Y. Umasankar, H. O'Neill, R.P. Ramasamy, High photo-electrochemical activity of thylakoid-carbon nanotube composites for photosynthetic energy conversion, Energy \& Environmental Science, 6 (2013) 1891-1900.

[15] H. Hamidi, K. Hasan, S.C. Emek, Y. Dilgin, H.-E. Akerlund, P.-A. Albertsson, D. Leech, L. Gorton, Photocurrent Generation from Thylakoid Membranes on Osmium-Redox-PolymerModified Electrodes, ChemSuschem, 8 (2015) 990-993.

[16] K. Hasan, Y. Dilgin, S.C. Emek, M. Tavahodi, H.-E. Akerlund, P.-A. Albertsson, L. Gorton, Photoelectrochemical Communication between Thylakoid Membranes and Gold Electrodes through Different Quinone Derivatives, Chemelectrochem, 1 (2014) 131-139. [17] M. Rasmussen, S.D. Minteer, Investigating the mechanism of thylakoid direct electron transfer for photocurrent generation, Electrochimica Acta, 126 (2014) 68-73.

[18] M. Rasmussen, S.D. Minteer, Thylakoid direct photobioelectrocatalysis: utilizing stroma thylakoids to improve bio-solar cell performance, Physical Chemistry Chemical Physics, 16 (2014) 17327-17331.

[19] P. Bombelli, R.W. Bradley, A.M. Scott, A.J. Philips, A.J. McCormick, S.M. Cruz, A. Anderson, K. Yunus, D.S. Bendall, P.J. Cameron, J.M. Davies, A.G. Smith, C.J. Howe, A.C. 
Fisher, Quantitative analysis of the factors limiting solar power transduction by Synechocystis sp. PCC 6803 in biological photovoltaic devices, Energy \& Environmental Science, 4 (2011) 4690-4698.

[20] P. Bombelli, T. Mueller, T.W. Herling, C.J. Howe, T.P.J. Knowles, A High PowerDensity, Mediator-Free, Microfluidic Biophotovoltaic Device for Cyanobacterial Cells, Advanced Energy Materials, 5 (2015) 1401299.

[21] R.W. Bradley, P. Bombelli, D.J. Lea-Smith, C.J. Howe, Terminal oxidase mutants of the cyanobacterium Synechocystis sp PCC 6803 show increased electrogenic activity in biological photo-voltaic systems, Physical Chemistry Chemical Physics, 15 (2013) 13611-13618.

[22] K. Hasan, H.B. Yildiz, E. Sperling, P.O. Conghaile, M.A. Packer, D. Leech, C. Hagerhall, L. Gorton, Photo-electrochemical communication between cyanobacteria (Leptolyngbia sp.) and osmium redox polymer modified electrodes, Physical Chemistry Chemical Physics, 16 (2014) 24676-24680.

[23] J.M. Pisciotta, Y. Zou, I.V. Baskakov, Light-Dependent Electrogenic Activity of Cyanobacteria, Plos One, 5 (2010) e10821.

[24] A.J. McCormick, P. Bombelli, A.M. Scott, A.J. Philips, A.G. Smith, A.C. Fisher, C.J. Howe, Photosynthetic biofilms in pure culture harness solar energy in a mediatorless biophotovoltaic cell (BPV) system, Energy \& Environmental Science, 4 (2011) 4699-4709. [25] K. Hasan, E. Cevik, E. Sperling, M.A. Packer, D. Leech, L. Gorton, Photoelectrochemical Wiring of Paulschulzia pseudovolvox (Algae) to Osmium Polymer Modified Electrodes for Harnessing Solar Energy, Advanced Energy Materials, 5 (2015) 1501100.

[26] M. Torimura, A. Miki, A. Wadano, K. Kano, T. Ikeda, Electrochemical investigation of cyanobacteria Synechococcus sp PCC7942-catalyzed photoreduction of exogenous quinones and photoelectrochemical oxidation of water, Journal of Electroanalytical Chemistry, 496 (2001) 21-28.

[27] T. Yasukawa, I. Uchida, T. Matsue, Microamperometric measurements of photosynthetic activity in a single algal protoplast, Biophysical Journal, 76 (1999) 1129-1135.

[28] M. Kasuno, M. Torimura, Y. Tsukatani, D. Murakami, S. Hanada, T. Matsushita, H. Tao, Characterization of the photoinduced electron transfer reaction from the photosynthetic system in Rhodobacter sphaeroides to an exogenous electron acceptor, Journal of Electroanalytical Chemistry, 636 (2009) 101-106.

[29] G. Longatte, H.-Y. Fu, O. Buriez, E. Labbe, F.-A. Wollman, C. Amatore, F. Rappaport, M. Guille-Collignon, F. Lemaitre, Evaluation of photosynthetic electrons derivation by exogenous redox mediators, Biophysical Chemistry, 205 (2015) 1-8. 
[30] G. Longatte, F. Rappaport, F.A. Wollman, M. Guille-Collignon, F. Lemaitre, Mechanism and analyses for extracting photosynthetic electrons using exogenous quinones - what makes a good extraction pathway?, Photochemical \& Photobiological Sciences, 15 (2016) 969-979.

[31] B. Rimbault, D. Esposito, D. Drapier, Y. Choquet, D. Stern, F.A. Wollman, Identification of the initiation codon for the atpB gene in Chlamydomonas chloroplasts excludes translation of a precursor form of the beta subunit of the ATP synthase, Molecular and General Genetics, 264 (2000) 486-491.

[32] A. Anderson, A. Laohavisit, I.K. Blaby, P. Bombelli, C.J. Howe, S.S. Merchant, J.M.

Davies, A.G. Smith, Exploiting algal NADPH oxidase for biophotovoltaic energy, Plant

Biotechnology Journal, 14 (2016) 22-28.

[33] X.M. Li, T.X. Liu, K. Wang, T.D. Waite, Light-Induced Extracellular Electron Transport by the Marine Raphidophyte Chattonella marina, Environmental Science \& Technology, 49 (2015) 1392-1399. 


\section{Figure Captions}

Figure 1. Simplified schemes of the photosynthetic machinery considered in this work. A) Green unicellular alga population in suspension. B) Representation of the green algae

Chalmydomonas reinhardtii. C) Scheme of a chloroplast containing thylakoid membranes. D) Photosynthetic chain within a thylakoid membrane. The dashed line traces the electron flow along from the PSII (water oxidation) to the final $\mathrm{CO}_{2}$ reduction. In short, light absorption induces Photosystem II (PSII) excitation. One of the possible PSII desexcitation pathways occur through a charge separation that leads to water oxidation. Several subsequent steps involving the plastoquinone (PQ)/plastoquinol $\left(\mathrm{PQH}_{2}\right)$ pool, the cytochrome $\mathrm{b}_{6} \mathrm{f}\left(\mathrm{b}_{6} \mathrm{f}\right)$ and the Photosystem I (PSI) eventually leads to and $\mathrm{CO}_{2}$ reduction. The electron transfer rate determining step occurs between the $\mathrm{PQ} / \mathrm{PQH}_{2}$ pool and the $\mathrm{b}_{6} \mathrm{f}$ complex.

Figure 2. Photograph of the set-up used in this work. Left : the spectroelectrochemical cell. The illumination zone is located at the bottom of the cell. Right : the whole set-up.

Figure 3. Current recorded as a function of the time (after baseline sustraction) at the carbon surface $(\mathrm{E}=650 \mathrm{mV}$ vs $\mathrm{Ag} / \mathrm{AgCl})$ from a suspension of Chlamydomonas Rheinaardti $\triangle$ PetA mutants $\left(10^{7}\right.$ cells.mL $\left.{ }^{-1}\right)$ in TAP (see experimental part) in presence of 2,6-DCBQ $40 \mu \mathrm{M}$ (dashed line) and $100 \mu \mathrm{M}$ (solid line). The period of illumination (incident light flow 340 $\left.\mu \mathrm{E} \cdot \mathrm{m}^{-2} \cdot \mathrm{s}^{-1}\right)$ is indicated.

Figure 4. Steady state current recorded during illumination with regard to the ratio between the area of the I-t curve and the illumination time $(t=1900 \mathrm{~s})$ for all the electrochemical experiments reported in this work with 2,6-DCBQ. 
Figure 1
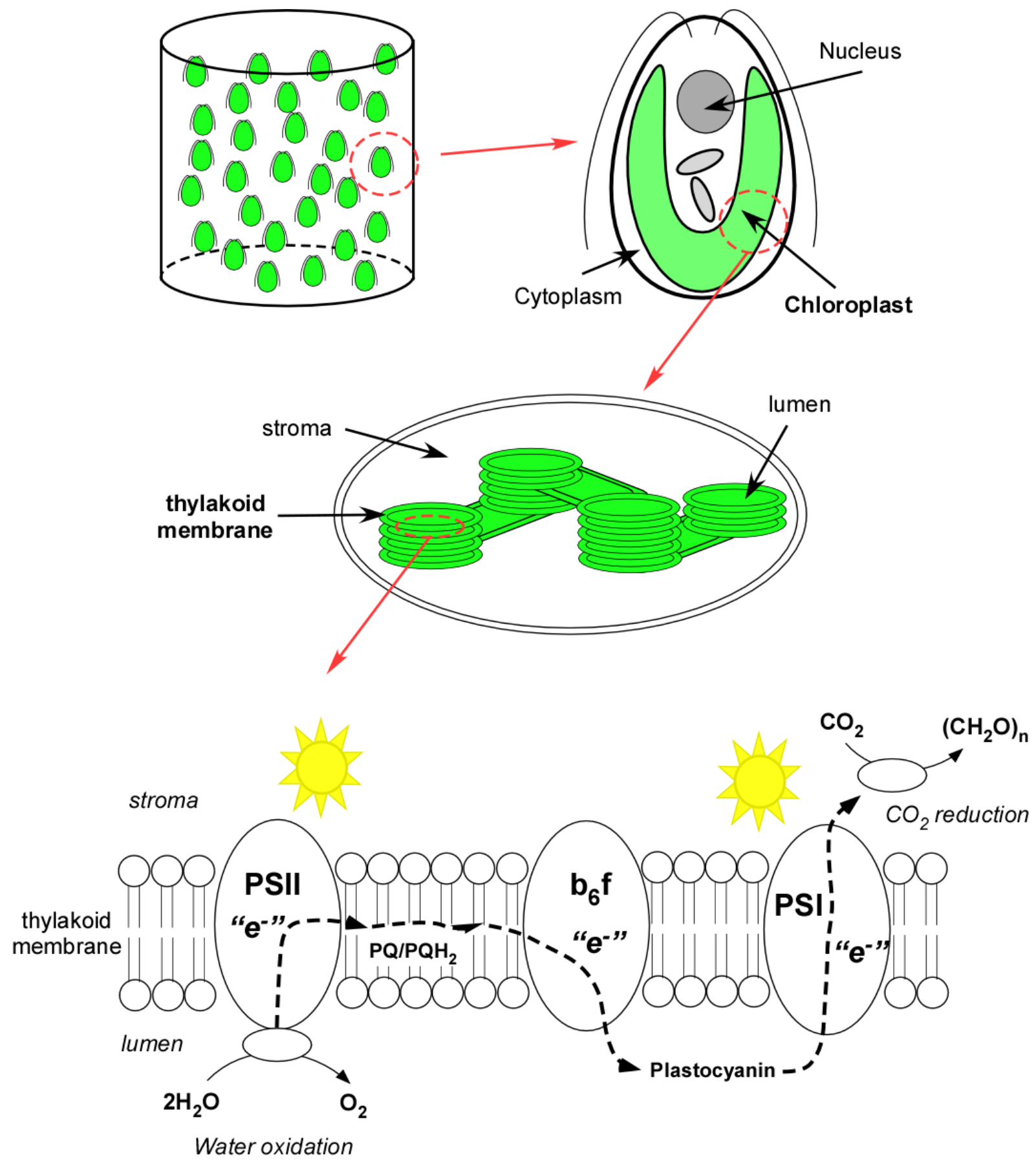

$<$ Inlinelmage1> 
Figure 2
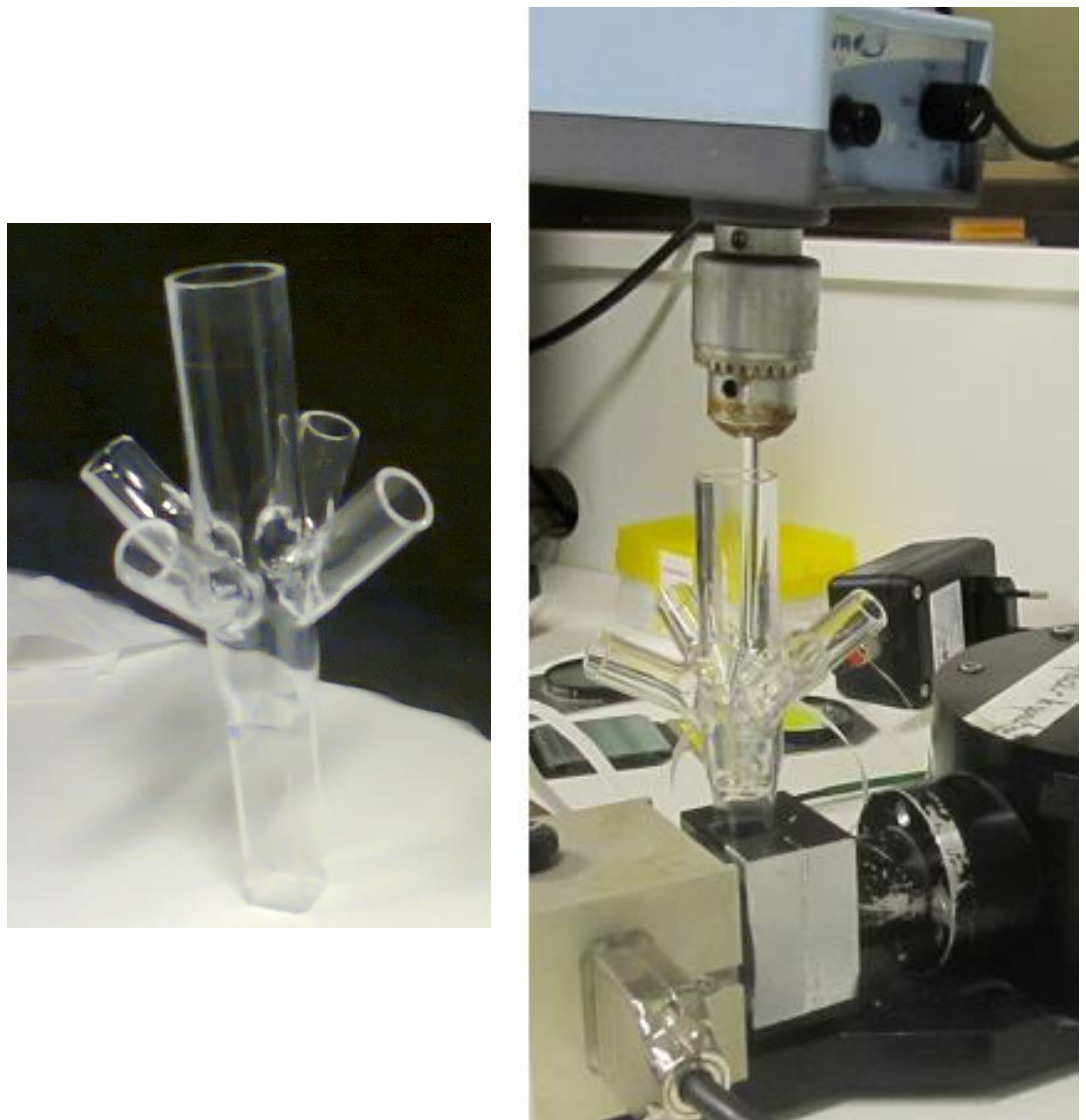

$<$ Inlinelmage2> 
Figure 3

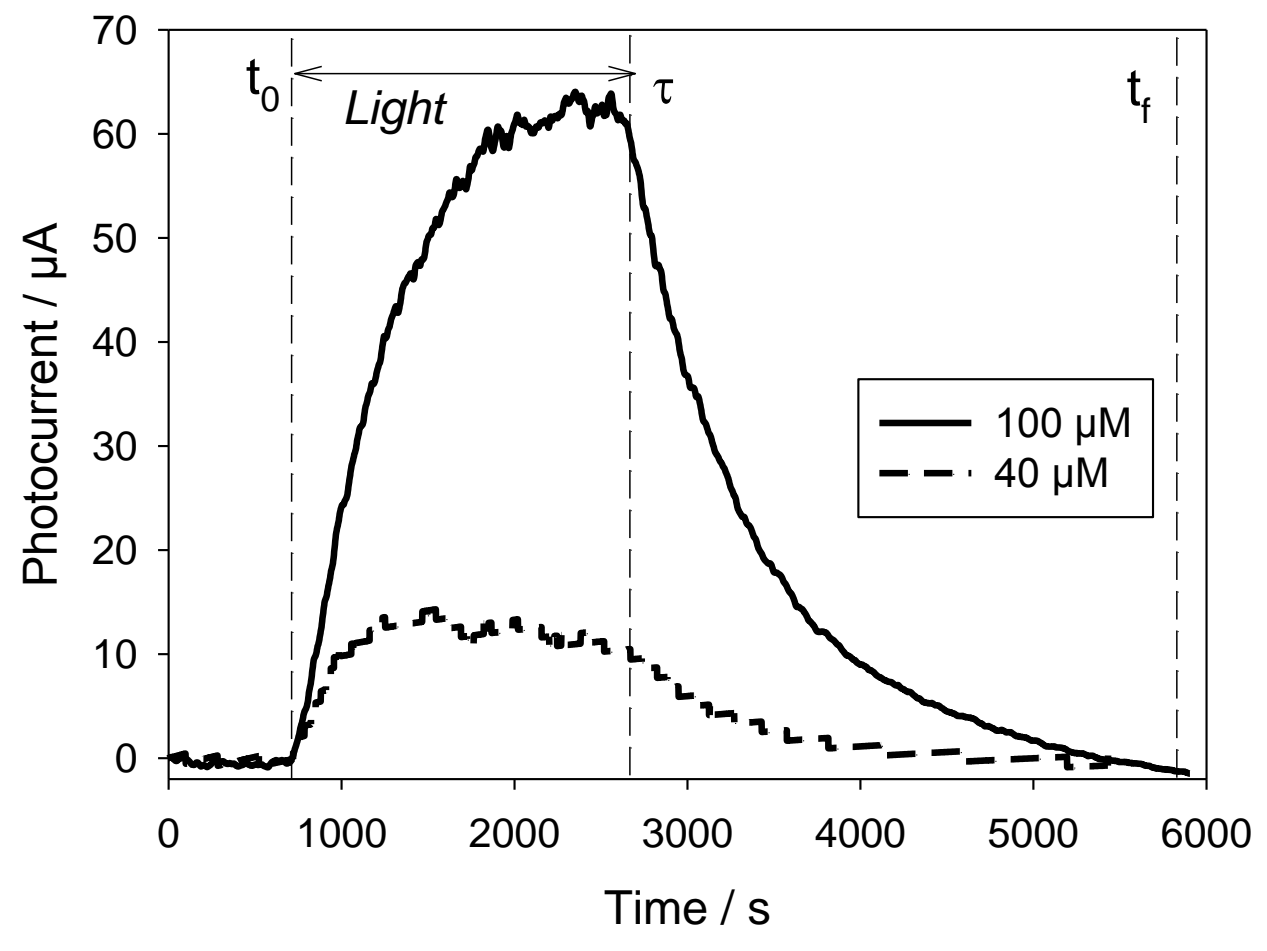

$<$ Inlinelmage3>

Figure 4

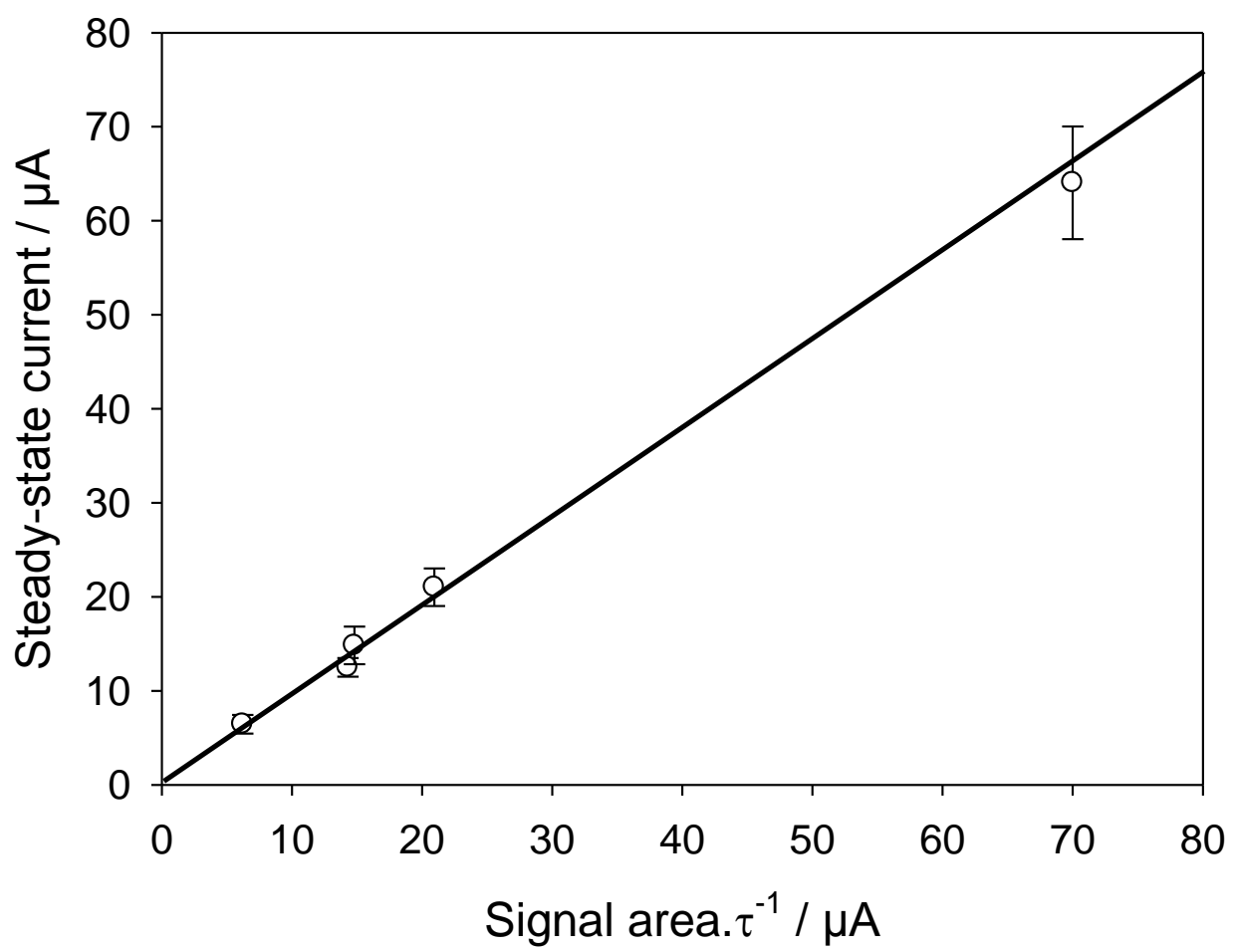

<Inlinelmage4> 
Table 1. Steady state photocurrent (in $\mu \mathrm{A}$ ) values (related to the light illumination of the algae suspension) as a function of the 2,6-DCBQ and incident light flow.

\begin{tabular}{|l|l|l|l|}
\hline$C\left(\mu \mathrm{mol} . \mathrm{L}^{-1}\right)$ & 100 & 75 & 40 \\
$\mathbf{I}^{\circ}\left(\boldsymbol{\mu E} \cdot \mathbf{m}^{-2} \cdot \mathbf{s}^{-1}\right)$ & & & \\
\hline $\mathbf{3 4 0}$ & $60 \pm 2$ & - & $12 \pm 1$ \\
\hline $\mathbf{1 3 5}$ & $20 \pm 2$ & $14 \pm 2$ & $5 \pm 1$ \\
\hline
\end{tabular}

